\title{
E-TEACHING AND -LEARNING IN CRISIS SitUATIONS: THEIR EFFECT ON NEW DIRECTIONS OF THINKING IN HighER EDUCATION
}

\author{
Nitza Davidovitch and Rivka Wadmany \\ Ariel University, Israel
}

\begin{abstract}
The COVID-19 year was a difficult and challenging year in all areas of life. The academic world as well was compelled, in a matter of days, to shift from face-to-face learning on campus to e-Learning from a distance, with no adequate preparation. Despite the difficulties generated by e-Learning and students' many complaints, the Israeli Council for Higher Education and institutions of higher education are preparing for a new era, where online courses will constitute an integral part of studies. The purpose of the study was to examine the attitude of lecturers and students to the benefits and shortcomings of e-teaching with its various aspects from a systemic, multi-institutional perspective. The study included 2,015 students and 223 lecturers from different academic institutions: universities, academic colleges of education, academic colleges of engineering, and private colleges.
\end{abstract}

The research findings show that only one third of the lecturers expressed a preference for $e$ Learning. With regard to the types of preferred e-lessons: $69 \%$ would prefer to teach theoretical classes online, while $42 \%$ would prefer to teach exercise classes online. Only 14\% would prefer to teach practical classes online, and only $19 \%$ would prefer to conduct workshops online. Lecturers were found to have more negative opinions of e-teaching than students: Two thirds of the lecturers $(60 \%)$ are not happy that e-Learning reduces their interpersonal interaction with the students and among the lecturers. The proportion of lecturers who lament the lack of social interaction is higher than that of students who feel this lack (40\%). About two thirds of lecturers noted the lack of social and emotional personal interaction with students and lecturers as one of the main shortcomings of e-Learning. Moreover, most of the lecturers do not perceive $e$ Learning as an advantage with regard to the quality of teaching and learning and only one third of the lecturers were of the opinion that e-teaching is on a higher standard than face-to-face teaching. Only one sixth of the lecturers were of the opinion that e-Learning is worthwhile for students with regard to their ability to handle the studies and the study material or to gain from the lessons. The study indicates the need for perceptual changes among the lecturers, such that they will reexamine the teaching and learning processes and adjust their role and fields of responsibility to the new opportunities provided by the technological tools and learning environment. The success of e-Learning requires suitable pedagogical educational approaches rather than copying teaching patterns from traditional frontal approaches to online teaching patterns. The research findings indicate the roles of the lecturer in the digital era, and particularly the role of the professionals responsible for teaching and learning in academic institutions, primarily with regard to the pedagogical aspects. The system of academic education has proven that beside the difficulties generated during the crisis, distance learning has many advantages such as the ability to study anytime and anywhere, efficient planning, and adapting the courses and study methods to the students. Nevertheless, the research findings prove that there is no alternative to personal contact, encounters between the teacher and students and among the students. E-learning constitutes a unique and powerful solution, but not an exclusive solution, and it is not necessarily appropriate for all disciplines and teaching and

David C. Wyld et al. (Eds): NLPTA, EDU, DSA, IoTE, VLSI, DPPR, ACITY, AIAA, CNDC - 2021 
learning goals. It appears that combining e-Learning with "face to face" learning can enhance the learning experience, the successes, and students' achievements. Advance preparation, as well as planning a new daily schedule on campus, might advance lecturers and students, in a gradual and structured way, to the challenging tasks of future teaching.

\section{KEYWORDS}

E-Learning, academic teaching, COVID-19, crisis situations, higher education

\section{INTRODUCTION}

We are witnessing significant processes, the transformation of pedagogical paradigms, and new ways of combining technology in processes of pedagogic development and in teaching [1-3]. Researchers note that it is now not up to us, and different institutions and organizations, including institutions of higher education, have no option of disregarding technological processes and the possibilities offered by distance learning. In this paper, we shall review leading and relevant trends affecting many differentglobal spheres (the labor market, the economy, politics, the environment) and we shall address their effect on the world of higher education [4].

There are two basic assumptions for thinking about changes in the world of higher education [56]:

1. Higher education does not operate in a vacuum. It is a sphere that is affected by the relevant circumstances. It is necessary to take into account such significant transformations even if they do not occur (at first) in higher education, rather in the surrounding spheres [7].

2. Academia is at present under criticism and strict inspection with regard to its status and contribution to the new world:

- Economy of time - How do students benefit from academic studies? Why is it worthwhile to invest time and money in higher education?

- "Face-to-face" encounters are notthe most important. There are many tools and means that support learning.

- Distance learning - A trend that began decades ago but has accelerated (digital articles and textbooks, audio books, recorded lectures, interactive course websites).

The option of academic studies without leaving home (including live lessons, asynchronous study material, and online exams) exists at present at all institutions in the world. Institutions are distinguished by the unique mix they generate within studies, between the synchronous and asynchronous components.

We are required to change the paradigms not only with regard to encounters on Zoom but rather also with regard to the entire learning process, through developing asynchronous components, improving learning environments, ways of evaluation, and others.

- Individually adapted teaching. Differentiation and a response to each student according to his or her level of knowledge and unique learning style. In addition, the introduction of adaptive technologies to studies raises the added value of individual adjustment both when presenting information and in the pedagogical solutions offered: determining the ratio of frontal encounters and Zoom encounters (expanding 
time and place), self-study and assignments on the course website, personal assignments, and others.

- Digital pedagogy that defines the goals of education and the image of students in the $21^{\text {st }}$ century in order to adapt them to the dynamic and changing circumstances in which students operate [8].

Soft skills - In an era when knowledge is up to the students and accessible to all, teaching and developing learning skills and other important skills that will allow students to do better at work and in the real world in any field they engage in, is very important [9].

The jobs of the future are still unknown and therefore enhancing skills such as problem solving, creativity, teamwork, time management, networking, and so on, will ensure capabilities relevant for the future world in all areas [10].

Experiential learning - In response to the criticism aimed at academia for its separation from the "field" and the practical world and in the wish to generate meaningful, experiential, and memorable learning for students, there is a demand to integrate more experiential learning. Learning that confronts students with real problems from the field and invites dealing with them, learning that combines familiarization with the practical world of the discipline and forming meaningful experiences. The technological development of virtual reality and augmented reality systems helps form a tangible experience for the students, from home as well [11].

Networked learning - As part of the global perception of transitioning from hierarchies to a network, networked learning is based on the premise that knowledge cannot belong to a single person and that no significant learning is produced by transferring knowledge from a single element to a group. Knowledge must be produced in a group by all its members.In this context, the lecturer not only imparts knowledge but rather mediates it, facilitating group learning [12].

- Artificial intelligence - This significant technological trend that has been growing rapidly in recent years, is finally beginning to permeate the world of higher education as well. Systems for managing learning are using the assistance of algorithms that analyze the method of operation utilized by learners in the environment, the difficulties and preferences for various media, and provide learners with adjusted feedback according to this algorithm analysis.

Teaching that encompasses data: Feedback on effectiveness, support activities, the pattern of learning in the course, data on the lesson and on the students - are a basis for determining indicators and recommendations for support activities.

The result: Creating a dynamic of constant improvement.

In the future: Developing an algorithm and analysis of learning patterns to explore learning in the course and individually [13].

The connection between academia and industry - Much criticism has been voiced with regard to the separation between the academic world and the practical and industrial world outside, which students encounter when completing their studies. Institutions of higher education that form a stronger connection between academia and industry will give themselves a relative advantage and a justification for choosing them over the competitors. Such a connection can occur through contents adapted to market needs, links between places of employment, shadowing, boot camps, residency programs for courses and students, and help in placement towards the end of studies [14]. 
- Alternative study models- As part of the premise whereby it is necessary to emphasize the returns and the added value that students receive from academic studies, the understanding that different students have different needs and that academia must generate interesting and diverse alternatives for studies is forming. Not only full degrees, also nanodegrees, training programs, structured programs for certain occupations or professions, and mainly more specific contents that are better tailored to the practical world that follows academia.

- Students' physical, mental, and social well-being- This trend raises the need to see the students from a more holistic and humane perspective. Distance teaching reinforces the emotional aspects involved in studies and every self-respecting institution must take into account the consideration of and response to these emotional aspects for the good of the studies. Blurring the boundaries between the home and workplace/place of studies, and the hardships added during the COVID-19 crisis, reinforce the conception of social-emotional learning and the need to grant students the security they need in order to be available for the study process.

- The current era urges people to remain on their toes - life-long learners. Learning occurs incessantly, as the changes and dynamic nature of life constantly encourage adjustment to the next thing. Many professions are disappearing and others emerging, requiring us all to leave out comfort zone and to learn at all times according to the needs and to our stage in life. No longer an initial degree and then working 40 years in the same place, rather changing needs, dynamic employment, and diverse studies adapted to the different stages in life.

\section{In summary - what is our added value as an institution and as lecturers?}

Institutions of higher education can no longer rest on their laurels and expect to continue existing and flourishing while disregarding their dynamic surroundings. Rethinking study contents, their relevance for the life of the students, new and varied methods of evaluation and learning, harnessing technology to recreate learning processes and adapt them to the learning methods and to learners' emotional aspects, all these will ensure that higher education is a meaningful and relevant element in the current era as well.

\section{The CurRent Study}

\subsection{Purpose of the Study}

To explore the attitude of lecturers to the benefits and shortcomings of e-teaching from different aspects and in a systemic, multi-institutional perspective.

\subsection{Research Questions}

1) What are the benefits and shortcomings of e-teaching on the cognitive dimension (interest, order and organization, and clarity) as perceived by students and lecturers?

2) What are the benefits and shortcomings of e-teaching on the academic-emotional dimension, with a focus on interpersonal interaction and the availability of the lecturers to the students?

3) What are the main difficulties of students in general, with a focus on deficient resources in particular, with regard to e-Learning?

4) What are the personal preferences of students and lecturers with regard to e-teaching and learning in general and by: type of lesson, approaches to distance learning and teaching, types of institutions of higher education, study departments, and types of lesson, and what factors affect this perception? 
5) Are there differences between students and lecturers with regard to the benefits and shortcomings of e-Learning?

\subsection{Research Population}

The study included 223 lecturers teaching at various academic institutions: universities, academic colleges of education, academic colleges of engineering, and private colleges. Of these, $51 \%$ were men and $49 \%$ women. Sixty-two percent held the rank of lecturer rank, 20\% the rank of teacher, and $18 \%$ the rank of professor. Sixty-five percent were teaching in faculties of social sciences and humanities and $35 \%$ in faculties of exact sciences. The study also included 2,015 students from different academic institutions: universities, academic colleges of education, academic colleges of engineering, and private colleges.

\subsection{Research Tools and Data Analysis}

A questionnaire that included statements related to the impact of e-Learning on the quality of learning and to the benefits and shortcomings of e-teaching and -learning.The questionnaire was constructed based on the cognitive-emotional model of best teaching devised by Hativa [15]. According to this theory, a good teacher has a teaching capacity that is comprised of two dimensions:

(1) The cognitive dimension: interest, order and organization, and clarity. Reliability: 0.79 .

(2) The academic-emotional dimension: interpersonal interaction and the availability of the lecturers for the students. Reliability: 0.73 .

Two other areas explored in the study were based on the model devised by Cohen and Davidovitch (2020):

(3) Worthwhileness and improving the student's learning capacity in e-teaching. Reliability: 0.71.

(4) Personal preference and perception of e-Learning by students and lecturers (by type of lesson, method of study, type of institution, department of studies, student convenience, and resources). Reliability: 0.84 .

The factors affecting students' preference for e-teaching as perceived by students and lecturers were also examined.

The questionnaire developed included 43 items that referred to four main areas described. The respondents were asked to rank their answers on a scale of 1 to 5 (where 1 means not at all and 5 means very much). In addition, the questionnaire included questions on personal, familyemployment, and academic/teaching background of the students and lecturers in the sample. The findings are presented below:

\subsubsection{Student Characteristics: Personal, Family-Employment, and Academic Background}

Of all the respondents, $46.8 \%$ were men and $53.2 \%$ women, where $87.7 \%$ were undergraduate students, $39.0 \%$ were not employed, $67.7 \%$ were single, and $31.1 \%$ married. In addition, $89.3 \%$ were Jewish, $8.4 \%$ with a high socioeconomic status, $68.0 \%$ a medium socioeconomic status, and $23.6 \%$ a low socioeconomic status. Almost all (90\%) noted that they have the necessary resources and tools for e-Learning. 


\subsubsection{Lecturers' Perception of E-Teaching}

Only $31 \%$ of lecturers in academia prefer e-teaching. The research findings indicatethat the rate of lecturers who lament the lack of social interaction is even higher than that of students who feel the same way. Most of the lecturers do not perceive e-learning as an advantage with regard to the actual quality of teaching and learning.

\subsubsection{Preference for E-Teaching by Type of Lesson}

With regard to the preferred type of e-lessons:

- $69 \%$ of lecturers prefer to teach theoretical classes online.

- $42 \%$ prefer online exercise lessons.

- Only $14 \%$ prefer online practical lessons.

- Only $19 \%$ prefer to conduct workshops online.

\section{Namely, lecturers have negative views of e-teaching, even more than do students.}

Two thirds of the lecturers are not happy that e-Learning reduces their interaction with the students and with their peers. The rate of lecturers who miss the social interaction is even higher than the rate of students who hold this opinion.About two thirds of the lecturers noted the lack of personal, social, and emotional interaction with students and lecturers, as one of the main disadvantages of e-Learning.

Most of the lecturers do not perceive e-Learning as an advantage with regard to the actual quality of teaching and learning.Only about one fifth of the lecturers are of the opinion that e-teaching is on a higher standard than face-to-face teaching.Only one sixth of the lecturers are of the opinion that e-Learning is worthwhile for students with regard to their ability to cope with the learning and the study material or to benefit from the lesson.

\section{Summary OF The Findings}

The research findings indicate that:

- Students and lecturers do not show a high preference for e-Learning during the COVID-19 crisis: Less than half the students and about one third of the lecturers expressed a preference for studying in this method.

- Students and lecturers noted the lack of personal interaction with students and lecturers as one of the main shortcomings of e-Learning/teaching conducted in their institution.

- One of the disadvantages of e-teaching/learning, which arose in the two populations, was the concern that students' score average or the average of lecturer evaluations, would be affected following the transition to e-Learning.

- $\quad$ Saving resources (such as: petrol for traveling to the academic institution, hours of standing in traffic jams, hours of waiting between lessons at the institution) is one of the benefits of eLearning as perceived by the students.

- Most of the students do not perceive e-Learning as providing them with an advantage with regards to the quality of learning. Notably, improving the ability to study online is the measure that most affects students' preference for e-Learning, but only $39 \%$ of students are of the opinion that e-Learning indeed gives them such an advantage. 
- Among the population of lecturers, the perceived worthwhileness of e-teaching for the students and the degree of interest, order, organization, and clarity in teaching, are factors that have a considerable impact on the preference for e-teaching, however less than half the lecturers are of the opinion that e-teaching has these qualities. Notably, older lecturers show less preference for e-teaching than do younger lecturers. They may have more difficulty adapting to teaching in this method.

- Both students and lecturers are of the opinion that e-Learning/teaching are not equally suitable for all types of lessons: Both populations are mostly of the opinion that a theoretical lesson can be learned via e-teaching, but few think that it is possible to take a workshop or practical lesson via e-Learning.

- The students prefer e-Learning in the synchronous online lesson approach over asynchronous e-Learning via recorded lectures, and some are of the opinion that the best way of studying online is by a combination of these approaches.

- About one tenth of the students report that there is a problem that prevents them from studying online. The main difficulty noted by the students is the lack of technology that enables implementation of e-Learning (computer, microphone, camera, etc.). Other difficulties indicated by the students are the lack of proper study conditions and the difficulty to adjust to e-Learning. Most of the students (90\%) noted that they have the necessary resources and tools for e-Learning.

- The students are of the opinion that use of technology is not done thoughtfully and does not affect the quality of teaching and learning processes. They claim that faculty members use it technically more than pedagogically.

\section{Discussion}

The study indicates the need for perceptual changes among the lecturers, such that they will reexamine the teaching and learning processes and adapt their role and fields of responsibility to the new opportunities afforded by the technological tools and learning environment. The success of e-Learning requires appropriate pedagogic educational approaches rather than copying teaching patterns from traditional frontal approaches to online teaching patterns. The research findings indicate the roles of the lecturer in the digital era, and particularly the role of the professionals responsible for teaching and learning in academic institutions, particularly in the pedagogical aspects.

The system of academic education has proven that beside the difficulties formed as a result of the crisis, distance learning has its advantages, such as the ability to study at any time and anywhere, efficient planning, adjusting the courses and manners of studying to the students. Nevertheless, the research findings prove that there is no replacement for personal contact and for the teacherstudent encounter and encounters between the students. E-Learning is a unique and powerful but not an exclusive solution and it does not suit all disciplines and ways of teaching. The combination of e-Learning with "face-to-face" learning can enhance the learning experience, as well as students' success and achievements. Advance preparation and planning a new schedule on campusmight boost the progress of lecturers and students in a gradual and structured way, for challenging tasks of teaching in the future.

\section{From theory to practice:}

- A need for perceptual change among the lecturers, such that they will reexamine the teaching and learning processes and adapt their role and fields of responsibility to the new opportunities afforded by the technological tools and learning environment. 
- The success of e-Learning requires appropriate pedagogic educational approaches rather than copying teaching patterns from traditional frontal approaches to online teaching patterns.

- The system of academic education has proven that beside the difficulties formed as a result of the crisis, distance learning has its advantages, such as the ability to study at any time and anywhere, efficient planning, adjusting the courses and manners of studying to the students.

- The need for personal contact and for teacher-student encounters and encounters between the students. E-Learning is a unique and powerful but not an exclusive solution, and it is not necessarily appropriate for all disciplines and ways of learning and teaching. It appears that the combination of e-Learning with "face-to-face" learning can enhance the learning experience, as well as students' success and achievements. Advance preparation and planning a new schedule on campus might boost the progress of lecturers and students in a gradual and structured way, for challenging tasks of teaching in the future.

\section{REFERENCES}

[1] Guri-Rosenblit, Sara. (2010) Digital technologies in higher education: Sweeping expectations and actual effects, Nova Science.

[2] Guri-Rosenblit, Sara. (2018) "E-teaching in higher education: An essential prerequisite for eLearning", Journal for New Approaches in Educational Research, Vol. 7, No. 2, pp93-97. doi: 10.7821/near.2018.7.298

[3] European Commission (2020) Digital Education Action Plan 2021-2027 - Resetting education and training for the digital age.

[4] Davidovitch, Nitza. \&R. Wadmany (2021) "E-learning in times of crisis - An incidental or facilitative event?" In Z. Sinuany-Stern (Ed.), Handbook of operations research and management science in higher education (pp. 453-479). Springer Nature.

[5] Almog, Tamar. \& Almog,Oz. (2020) Academia: All the lies: What went wrong in the university model and what will come in its place. YediotSfarim. [Hebrew]

[6] Katz, Israel. \& Gail. Talshir (Eds.) (2019) Lighthouse or ivory tower? The Israeli academy: Between challenging openness to defensive seclusion. Resling. [Hebrew]

[7] World Economic Forum. (2020) The Future of Jobs Report 2020. World Economic Forum.

[8] Wadmany, Rivka. (2017) “Digital pedagogues' in the information era”, In R. Wadmany (Ed.), Digital pedagogy - from theory to practice (pp. 11-16). Mofet Institute. [Hebrew]

[9] Contact North (2020) A new pedagogy is emerging, and online learning is a key contributing factor (August 4).

[10] Frankiewicz, Becky.,\&Tomas. Chamorro-Premuzic (2020) "Digital transformation is about talent, not technology", Harvard Business Review, Vol. 6.

[11] NeborskyNEgorValentinovich. Boguslavsky Mikhail Victorovich, Ladyzhets Natalya Segreevna\&Naumova Tatyana Albertovna(2020) "Digital transformation of higher education: International trends",Advances in Social Science, Education and Humanities Research, Vol. 437, pp393-398.

[12] Wahab, Ali. (2020) "Online and remote learning in higher education institutes: A necessity in light of COVID-19 pandemic," Higher Education Studies, Vol. 10(3),16-35.

[13] Nichols, Mark. (2020). Transforming universities with digital distance education - The future of formal learning, Routledge.

[14] Pelletier, Kathe.,Malcolm. Brown, D.Christopher Brooks, MarkMcCormack, Jamie Reeves, NicholeArbino, Aras Bozkurt, Steven Crawford, Laura Czerniewicz, Rob Gibson, Katie Linder, Jon Mason, VictoriaMondelli, (2021),EDUCAUSE Horizon Report Teaching and Learning Edition (pp. 4-50).

[15] Hativa nira (2015). What does the research say about good teaching and excellent teachers? Hora'ahBa'academya, 5, 50-55. [Hebrew]

(C) 2021 By AIRCC Publishing Corporation. This article is published under the Creative Commons Attribution (CC BY) license. 